\title{
Tradição e modernidade: 0 sistema de comunicação japonês
}

\section{Carlos Henrique Demarchi}

Universidade Estadual Paulista, Bauru, SP, Brasil

ORCID: https://orcid.org/0000-0002-4550-0135

\section{Resumo}

A caracterização do sistema de comunicação nipônico é um dos aspectos centrais do livro "Mídia no Japão", recém-lançado pela FAC-UnB. A obra analisa como, em meio à convergência tecnológica, a mídia japonesa desenvolveu um modelo peculiar de comunicação, centrado no conglomerado público NHK (Nippon Hoso Kyokai), nos grupos nacionais kereitsu e na adaptação ao avanço dos serviços de streaming. Por fim, traz reflexões para o Brasil, que adotou o sistema japonês de televisão digital.

\section{Palavras-chave}

Mídia. Políticas de comunicação. Convergência tecnológica. NHK. Sistemas de comunicação.

NAZARENO, Claudio. Mídia no Japão: como as comunicações do arquipélago sobrevivem à globalização e à internet. Brasília: FAC-UnB, 2020.

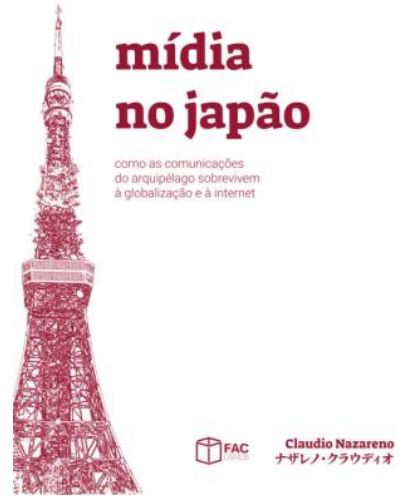

Existe uma vasta literatura para explicar como funcionam os sistemas de comunicação em países europeus, nos Estados Unidos (HALLIN; MANCINI, 2004) e na América Latina. Por outro lado, pouco ainda se conhece acerca do modelo de comunicação existente em países orientais. 
Com o mérito de preencher esta lacuna, acabou de ser lançado no Brasil o livro eletrônico "Mídia no Japão: como as comunicações do arquipélago sobrevivem à globalização e à internet", de autoria de Claudio Nazareno, doutor em Estudos em Filmes e Televisão pela University of Roehampton (Inglaterra) e atualmente consultor legislativo nas áreas de ciência e tecnologia, comunicações e informática da Câmara dos Deputados.

O livro se insere no campo das políticas de comunicação e está dividido em nove capítulos. A obra capta muitas peculiaridades do Japão, que saiu de um passado medieval e rapidamente adentrou em processo de modernização, aspecto que sobressai no segmento midiático do país no cenário pós-2ª Guerra Mundial.

É relevante entender naquele contexto a formação dos grupos nacionais de comunicação - os arranjos kereitsu, que congregam empresas de vários setores econômicos. Segundo o autor, em um ambiente regulatório liberal, “[...] a prática nipônica dessas empresas interligadas não reduziu a competição no setor de radiodifusão." (NAZARENO, 2020, p. 100).

Graças a esses arranjos empresariais, a mídia comercial alcançou uma interdependência sem precedentes. Merece destacar ainda a capacidade de influência das agências de publicidade, casos da Dentsu e Hakuhodo. No arquipélago, as agências atuam como agentes reguladoras da competição na televisão, evitando, deste modo, o surgimento de empresas radiodifusoras dominantes, como é comum no Brasil.

Evidências para a construção de um sistema próprio de comunicação podem ser percebidas a partir dos marcos legais, que trazem a ênfase, no processo de reconstrução do país no pós-Guerra, no bem-estar público como objetivo da comunicação, assim como estar presente em todas as regiões do país. Em leis mais recentes, também se previu a internacionalização dos sinais de transmissão e o desenvolvimento de ordem tecnológica.

A convivência entre as corporações privadas e o sistema público de comunicação é outra peculiaridade japonesa. E aqui reside um dos pontos de destaque do livro - o conglomerado público NHK (Nippon Hoso Kyokai), oriundo da Rádio de Tóquio.

O sistema público de TV japonês detém autonomia financeira decorrente de taxas anuais oriundas de contratos para cada residência, pois esses são obrigatórios para a recepção dos canais terrestres e de satélite. Diferente na missão se comparado à $\mathrm{BBC}$, o modelo de gestão japonês assemelha-se ao britânico.

Ao contrário do Brasil, onde há várias emissoras do campo público e a Constituição Federal diferencia os sistemas público, privado e estatal, no Japão a comunicação pública é 
exercida de modo exclusivo pela NHK. Ainda que o país não conte com um órgão regulador, há instrumentos de participação e acompanhamento da programação dos canais, com regras e grande responsabilidade social no tocante à radiodifusão pública.

Mesmo com a globalização, as emissoras japonesas souberam se adaptar à chegada das plataformas digitais, mantendo as estruturas tradicionais de comunicação e resultados favoráveis de audiência.

A obra é repleta de dados sobre o alcance das plataformas de televisão, nas modalidades tecnológicas de televisão terrestre, satélite aberto, DTH, cabo e IPTV (NAZARENO, 2020). Com um mercado audiovisual posicionado entre os maiores do mundo, com forte presença na indústria cinematográfica, o Japão se reinventa para fazer frente aos novos serviços de streaming distribuídos pela internet, estes últimos cada vez mais presentes e beneficiados pela infraestrutura de telecomunicações do arquipélago.

Claudio Nazareno recorreu a métodos combinados de pesquisa, incluindo a realização de entrevistas com atores de diversos setores de comunicação, entre eles produtores de conteúdo, empresários de jornais e canais de TV, representantes do governo e do Parlamento e acadêmicos, além de pesquisa bibliográfica. A pesquisa foi desenvolvida junto ao Instituto Iberoamericano da Universidade Sofia, em Tóquio.

De forma didática, trechos das entrevistas aparecem inseridos ao longo das 153 páginas da obra. Os atores principais envolvidos nas políticas de comunicação do setor estão no capítulo "As esferas de regulação". Já em "O cenário atual em números", Nazareno reuniu dados estatísticos das receitas dos segmentos audiovisuais, incluindo a TV, o cinema e a internet, analisando as implicações dos dados coletados.

A última parte do livro traz correlações entre o sistema nipônico de comunicação e o Brasil. Neste percurso, analisa os desdobramentos que cercam a parceria Brasil-Japão, firmada em 2006, na escolha do padrão de televisão digital (padrão ISDB).

O autor argumenta que, em geral, “[...] a adoção da tecnologia digital, assim como nos demais países, decorre de uma lógica que alia a renovação tecnológica e a necessária atualização da radiodifusão para encarar os atuais tempos digitais, com a movimentação da economia (pela necessidade de realização de investimentos maciços)." (NARAZENO, 2020, p. 85). Espera-se, segundo essa lógica, mais recursos para o crescimento e oferta de novos serviços. 
Não obstante, o modelo escolhido pelo Brasil veio por “[...] apenas replicar o já existente na televisão analógica." (NAZARENO, 2020, p. 90), o que impediu a abertura de espaço para novos canais na multiprogramação.

Deste modo, infere-se que a digitalização em solo brasileiro foi adotada como forma de evolução tecnológica aos segmentos de radiodifusão já existentes. No Japão, ao contrário, os cidadãos dispõem de mais opções dentre os grandes meios de comunicação.

Uma das contribuições de "A mídia no Japão" está em discutir a construção de um modelo de comunicação não verificado em outros lugares do planeta. Um caso peculiar em que a tradição e a modernidade estão entrelaçadas em um mundo cada vez mais globalizado e digital.

\section{Referências}

HALLIN; Daniel; MANCINI, Paolo. Comparing media systems: three models of media and politics. Cambridge: Cambridge University Press, 2004.

NAZARENO, Claudio. Mídia no Japão: como as comunicações do arquipélago sobrevivem à globalização e à internet. Brasília: FAC-UnB, 2020.

\section{Autoria para correspondência}

Carlos Henrique Demarchi

carlos.demarchi@unesp.br

\section{Como citar}

DEMARCHI, Carlos Henrique. Tradição e modernidade: o sistema de comunicação japonês. Intexto, Porto Alegre, n. 52, e-103374, jan./dez. 2021. DOI: http://dx.doi.org/10.19132/1807-8583202152.103374

Recebido em 24/05/2020

Aceito em $18 / 07 / 2020$ 